\title{
Bile duct injuries after cholecystectomy, analysis of constant risk
}

\author{
Jair Díaz-Martínez, Oscar Chapa-Azuela, Jorge Alberto Roldan-García, and Gustavo Alain Flores-Rangel
}

\author{
Hepato Pancreato Biliary Clinic, Hospital General de Mexico, Mexico City, Mexico
}

\begin{abstract}
Backgrounds/Aims: The bile duct injuries are the most severe complications that occur after the surgical manipulation of the bile duct. The hepaticojejunostomy remained as the best treatment. Several factors identified that affect the result. This study aimed to analyze and identify risk factors that affected the evolution of these patients. Methods: A retrospective, observational study was conducted from February 1998 to June 2017. We included all patients with bile duct injuries who required surgical treatment. Results: We found 79 patients. The majority had a Bismuth type III in $35.4 \%(n=28)$. The morbidity of the Hepaticojejunostomy was $19 \%(n=15)$. In short-term follow-up, the main complications were cholangitis $11.4 \%(n=9)$ and bile leak $10 \%(n=8)$. In the long-term follow-up, in $2.5 \%(n=2)$ stricture was presented. On the comparison between postoperative and preoperative parameters, biliary peritonitis after a cholecystectomy $(p=0.02)$ was an independent predictor of postoperative morbidity $(p<0.05)$. Conclusions: In the treatment of bile duct injuries, different factors affect their outcomes. Our results show that infectious complications continue to affect the results of the treatment of bile duct lesions. (Ann Hepatobiliary Pancreat Surg 2020;24:150-155)
\end{abstract}

Key Words: Bile duct; latrogenic injuries; Gallbladder; Cholecystectomy

\section{INTRODUCTION}

The bile duct injuries (BDI) main the most severe complications that occur after the surgical manipulation of BDI. ${ }^{1-3}$ Most of these presented after cholecystectomy. ${ }^{2,3}$ The reported incidence remains from 0.3 to $0.6 \%$. Only in the United States, 400 BDI are reported annually. ${ }^{3-7}$ BDI can present different manifestations from biliary fistula, persistent jaundice to cholangitis, biliary peritonitis, abdominal sepsis, cirrhosis, and even death. ${ }^{6}$

The hepaticojejunostomy remained the first option in this type of injury, being more time without stenosis. ${ }^{2,3,6}$ However, several factors identified that affect the result in the repair of the BDI. The biliary peritonitis, local inflammation, sepsis, and the early repair time after BDI are associated with worse outcomes and inclusive considered as relative contraindications. ${ }^{2,3,6,7}$

However, in the literature, there are a few specific studies in the identification of these risk factors, especially in Latin America, where there are a few kinds of research in this area. Therefore, this study aimed to analyze and evaluate long-term follow-up and identify the risk factors that affected the evolution in postoperative patients of biliodigestive anastomosis after BDI.

\section{MATERIALS AND METHODS}

\section{Study design}

The local research committee approved the following study. The retrospective study was conducted from February 1998 to June 2017. All patients referred to our center for presenting major BDI. We analyzed different variables as demographic, pre-surgical diagnosis, type of bile duct injury based on the Bismuth classification, and the time elapsed between the injury and the definitive treatment. ${ }^{8}$ The variables of the surgical procedure included surgery time and bleeding. Postoperative variables included complications, follow-up time, evolution, and mortality. We excluded patients who required only endoscopic, interventional radiological or with minor biliary leaks, and all patients without a complete follow-up.

Received: September 25, 2019; Revised: January 20, 2020; Accepted: January 20, 2020

Corresponding author: Jair Díaz-Martínez

Hepato Pancreato Biliary Clinic, Hospital General de Mexico, Dr Balmis 148, Col Doctores, Mexico City 06726, Mexico Tel: +01777187894, Fax: +015530373911, E-mail: diazjairmd@gmail.com

Copyright (C) 2020 by The Korean Association of Hepato-Biliary-Pancreatic Surgery

This is an Open Access article distributed under the terms of the Creative Commons Attribution Non-Commercial License (http://creativecommons.org/ licenses/by-nc/4.0) which permits unrestricted non-commercial use, distribution, and reproduction in any medium, provided the original work is properly cited. Annals of Hepato-Biliary-Pancreatic Surgery • pISSN: 2508-5778 - elSSN: 2508-5859 


\section{Clinical evaluation}

The patient's files reviewed. All patients were evaluated by a multidisciplinary team that included (surgeons, radiologists, endoscopists, nutritionists and anesthesiologists). The same surgical team operated the patients. On admission, the radiological evaluation was performed using percutaneous transhepatic cholangiography for revision of the lesion and control of jaundice or biliary leak.

\section{Description of biliary technique}

The reconstruction of the biliary tract performed by Roux-en-Y hepaticojejunostomy. ${ }^{2,3,5,6}$ After meticulous care, the bile duct was dissected, identifying the remaining bile duct. Then the hepatic hilum was dissected, and in some cases, also the hilar plate was dissected. The percutaneous transhepatic catheter identified, and it used as a guide for the dissection. Subsequently, it was cut above the remaining duct for radiological control after surgery and control in the case of fistula. Anastomotic hepaticojejunostomy with running sutures performed in a single plane, starting with the posterior wall and continuing with the anterior wall. In the case of smaller caliber anastomosis through separate hepatic ducts, interrupted sutures were used. Penrose drainage placed at the anastomosis level in all cases.

\section{Postsurgical evaluation and follow-up}

The patients evaluated through clinical evaluation and performance of liver function tests. The percutaneous transhepatic catheter removed after 2-4 weeks in the absence of a biliary leak. In the case of presenting a biliary leak, the catheter remained until the improvement. The follow-up performed after discharge subsequently was evaluated monthly, and then annually. Complications divided in early, those that occurred within a period of fewer than 30 days and late those that occurred after 30 days.

The correlation of overall postoperative morbidity, included anastomotic leakage, biliary peritonitis, anastomotic stricture, cholangitis, and reoperation analyzed concerning preoperative parameters such as time between injury and definitive treatment, reoperation at the hospital where the injury occurred, bile peritonitis after cholecystectomy, and use of post-surgical drainage.

\section{Statistical analysis}

We use T-student for continuous variables for catego- rical variables Chi-square, ANOVA, and logistic regression to perform the multivariate analysis. A $p$-value $\leq$ 0.05 (confidence interval of $95 \%$ ) was considered statistically significant. All statistical analyses were performed using the program IBM Statistical Package for Social Sciences (SPSS, Statistics version 24.0, Inc, Chicago, IL).

\section{RESULTS}

\section{Patient characteristics}

In the period studied, we found 79 patients who underwent biliodigestive anastomosis. Of these, 60 (75.9\%) were female, and $19(24.1 \%)$ male. The average age was 37 years (range, 12-75 years) and body mass index (BMI) was 26.41 (range, 17.22-34.72). Comorbidities found in 5 patients $(6.3 \%)$, four patients with type 2 diabetes, and one patient with diabetes and systemic arterial hypertension. Demographics characteristics of our patients shown in Table 1.

Open cholecystectomy was performed in the most patients $(62 \%, n=49)$, in 22 patients $(27.9 \%)$ laparoscopic, and only in $8(10.1 \%)$ converted cholecystectomy. In the majority of patients, the bile duct injury was not recognized during the cholecystectomy $(87.3 \%, n=69)$. Just in 10 patients $(12.6 \%)$, the injury noticed intraoperatively, and in 5 patients $(6.35 \%)$, the repair attempted. The diagnosis found in the initial cholecystectomy was mostly acute cholecystitis in $81 \%$, without finding significance by type of diagnosis. Before being referred to our hospital, 21 patients $(26.6 \%)$ were re-operated. The most frequent cause was a biliary leak $(21.51 \%, \mathrm{n}=17)$ followed by bleeding $(3.79 \%, \mathrm{n}=3)$ and in 1 patient $(1.26 \%)$ to try the bile duct reparation.

Table 1. Demographics characteristics of our patients

\begin{tabular}{lcc}
\hline \multicolumn{1}{c}{ Variable } & $\mathrm{n}=79$ & $\%, \mathrm{SD}$ \\
\hline Age (mean, SD) & 37 & $12.59 \mathrm{SD}$ \\
Gender (female, \%) & 60 & $75 \%$ \\
Comorbidities Diabetes II (\%) & 5 & $6.3 \%$ \\
Body mass index (mean, SD) & 26.41 & $3.57 \mathrm{SD}$ \\
Type of injury Bismuth classification & & \\
Bismuth II (\%) & 23 & $29.1 \%$ \\
Bismuth III (\%) & 28 & $35.4 \%$ \\
Bismuth IV (\%) & 14 & $17.7 \%$ \\
Bismuth V (\%) & 4 & $5.1 \%$ \\
\hline
\end{tabular}

SD, Standard deviation 
At the time of admission to the HPB clinic, the patients were treated by our multidisciplinary team. In 49 patients (62\%), percutaneous transhepatic catheter drainage for correct identification of the injury placed. In $24.1 \%$ ( $n=$ 19) preoperative drainage was not used. Without finding significance in the comparison by type of drainage.

\section{Surgery conditions}

For the correct identification of the injuries in our surgical team, we use the Bismuth classification. Most patients had a Bismuth type III $(35.4 \%, n=28)$, followed by type II $(29.1 \%, n=23)$, type IV $(17.7 \%, n=14)$ and type $\mathrm{V}(5.1 \%, \mathrm{n}=4)$. The repair of the bile duct made after a median of 84 days (range, 0-292). In all cases, Roux-en-Y Hepaticojejunostomy free tension anastomosis was carried out. The average time was 5 hours (range, 3-12 hours). The normal bleeding was 350 milliliters (range, 90-2000 ml). Only $14 \%$ of patients required trans-operative transfusion. Without finding significance between bleeding and surgery time. The average hospital stay in days was 11.46 (range, 4-41 days). After surgery, only one patient (1.3\%) required a hospital stay in the intensive care unit (ICU) due to biliary peritonitis and pneumonia.

\section{Outcomes}

The average follow-up was 16 months (range, 3 months-
19 years). Follow-up was divided in a short time, which included complications within the first 30 days and long-term complications after 30 days. Outcomes of hepaticojejunostomy shown in Table 2 . The morbidity was $19 \%(n=15)$. In the short-term follow-up, the main complications were cholangitis in $11.4 \%(\mathrm{n}=9)$. These patients responded successfully with medical management. Eight patients $(10 \%)$ presented bile leaks, two patients $(2.5 \%)$ presented biliary peritonitis, and three patients $(3.8 \%)$ presented abscess. Patients with bile leaks continued with a trans-hepatic catheter. In the case of biliary peritonitis and abscesses, an additional percutaneous catheter was placed in the collection site to perform adequate drainage.

After a long-term follow-up, two patients (2.5\%) developed a late anastomotic stricture. These strictures required serial dilatations without requiring re-intervention during follow-up. In the multivariate analysis of the preoperative variables, we found that biliary peritonitis after a cholecystectomy $(p=0.02)$ was an independent predictor of postoperative morbidity $(p<0.05)$. The time between injury and definitive operation $(p=0.69)$, the intraoperative time ( $p=0.45)$, the intraoperative bleeding $(p=0.22)$, use of postsurgical drainage $(p=0.37)$, did not show a statistically significant correlation to overall postoperative morbidity of the Hepaticojejunostomy $(p<0.05)$. We report a success rate of $97.5 \%$ and a mortality of $0 \%$.

Table 2. Outcomes of hepaticojejunostomy

\begin{tabular}{lcc}
\hline & $\mathrm{N}=79$ & $\%, \mathrm{SD}$ \\
\hline Transoperatory & & $\mathrm{SD} \pm 431.43$ \\
Time to repair & 84 days & $\mathrm{SD} \pm 82.14$ \\
Time of surgery & Five horas & $\mathrm{SD} \pm 322.68$ \\
Bleeding & $350 \mathrm{ml}$ & \\
Short-term complications $<30$ days & & $10 \%$ \\
Anastomotic leakage & 8 & $2.5 \%$ \\
Biliary peritonitis & 2 & $0.0 \%$ \\
Sepsis & 0 & $3.8 \%$ \\
Intrabdominal abscess & 3 & $11.4 \%$ \\
Cholangitis & 9 & $0 \%$ \\
Early reoperation & 0 & $0 \%$ \\
Mortality & 0 & $0 \%$ \\
Long term complications $>30$ days & & $0 \%$ \\
Incisional hernia & 0 & $2.5 \%$ \\
Late reoperation & 0 & $0 \%$ \\
Stricture of HJ & 2 & 0 \\
Mortality & 0 & \\
\hline
\end{tabular}

SD, Standard deviation 


\section{DISCUSSION}

Biliary tract injuries are severe complications with high morbidity that considerably reduce the quality of life. ${ }^{9,10}$ As reported by the literature, unfortunately, these injuries are increasing due to the high frequency of cholecystectomies worldwide. ${ }^{11}$ In our series, we found that these injuries preferentially occur in females in the fourth decade of life, similar to reported in the literature. This situation is according to the higher incidence of diagnosis of cholelithiasis in females in this age range, and therefore more significant accomplishment of cholecystectomies. ${ }^{12}$

Unlike that reported in the majority of studies worldwide, as well as by Bobkiewicz et al., ${ }^{13}$ which reports that $82.6 \%$ of injuries occur in laparoscopic cholecystectomies, in our series, the injuries were mostly open cholecystectomies, up to $62 \%$. This is even though currently, the "gold standard" for the treatment of cholelithiasis is laparoscopic cholecystectomy. This reflected an essential difference with the global literature and caused by the fact that in our environment, open cholecystectomy continues to be an option in hospitals where there is little laparoscopic equipment or even little training to perform these procedures. $^{13}$

In our cohort, only $12.6 \%$ of the lesions were identified in the transoperative period, lower than that found in the literature and very different from that reported by Rystedt et al., ${ }^{14}$ which reports in their work that these lesions can be identified up to $89 \%$ in the transoperative time. Referring to the classification, one of the most widely used for these injuries is the Bismuth classification, which we use in our service. Based on this classification, the most frequent lesions were type II and type III. That happend because we are a reference center for HPB surgery, and we receive patients with biliary tract injuries that are more severe and higher than other centers. ${ }^{4,8}$

As reported in the global literature, a free tension Roux-en-Y hepaticojejunostomy is still a safe and effective treatment, which has a lower rate of stricture, representing the best option in these patients in the long term. In our experience, we agree with these data, and for us, this surgery represents the best option in this type of injury. ${ }^{15}$ In our series, the transoperative time, as well as the bleeding, was acceptable, requiring transfusion of blood products by $14 \%$.
In the treatment of this type of patient, it is essential to reduce complications in the short and long term, thus allowing a better quality of life. These complications vary depending on the center where they are performed, decreasing in HPB surgery reference centers. In a multi-institutional analysis of risk factors using NSQIP of the morbidity and mortality of hepaticojejunostomy was reported the morbidity of $26.3 \%{ }^{16}$ In our cases, on average, the overall morbidity was $19 \%$. Of these, the most frequent complications were cholangitis and bile leak. Depending on the center, cholangitis reported in 5 to $27 \%$; in our center, this complication occurred in $11.4 \%$, managed conservatively. Another of the critical biliary complications to consider is biliary leakage, despite the experience of the center and the care that carried out the biliary leakage remains a significant comorbidity, some reference centers in HPB surgery have obtained success by decreasing this figure up to $5.7 \%$, in our series it was $10 \%$, being handled in all cases with transhepatic catheter without the need for reintervention. ${ }^{17}$

In our experience, we follow up annually and later for life to make sure we capture long-term complications. In the long-term follow-up, the most important thing is the stenosis that represents the effectiveness of the treatment. This figure has decreased as the experience of the reference center increases. In our center, we have achieved this efficiency by reporting this figure to $2.5 \%$. No patients require reoperations, the two patients who presented strictures, were successfully resolved with serial dilatations. This fact is in agreement with multiple studies that report that strictures can be treated successfully through this route without necesary reoperation. ${ }^{2}$

About concerning the analysis of the variables that influenced general morbidity, numerous studies have reported that time and intraoperative bleeding do not influence the outcome, in the same way, we found no relationship in the comparison. ${ }^{2}$ Regarding the use of postsurgical drainage, different studies have reported that the use of tutors increases the incidence of biliary leakages and postoperative complications. In our experience, we use stents above the anastomosis and never leave them tansanastomotic. In our series, we found no relationship between the use of tutors and biliary leakages in the postoperative morbidity. ${ }^{18}$ One of the most studied factors is the time interval between the onset of bile duct injury and 
the time it takes to perform the definitive treatment. The influence of this period on the results of subsequent treatment remains controversial. In our series, this interval was, on average, 12 weeks. In our country, this interval also influenced by different factors such as low patient resources to move to hospitals specialized in HPB surgery, among others. As reported in the literature, in our series, this interval also compare it with the morbidity without finding significance. ${ }^{19}$

The presence of infectious complications remains essential when deciding to operate theses patients. In our population, we found that the presence of biliary peritonitis and infectious complications was an independent variable, and it is still a factor that influences the results of the surgical outcome. According to what is reported by the literature, we can say that the treatment part of these patients is a timely shipment to a hospital center that has training in HPB surgery. ${ }^{20}$

The mortality reported in our series was zero, which attributed to specialized and multidisciplinary management, which agrees with the literature that reports the importance of specialized management in a reference center in HPB surgery. ${ }^{20}$ Controversies about the treatment of these patients continue, however, the control of sepsis, biliary peritonitis, and timely referral to patients, a multidisciplinary approach in a center with experience in this type of case, can improve the results and improve morbidity and survival and is an essential and recommended step when making decisions in this type of patients. ${ }^{21,22}$

Bile duct injuries remain severe complications of biliary tract surgery. Different factors affect their outcomes. Our results show that infectious complications continue to affect the results of the treatment of bile duct lesions. More studies with longer follow-up are still necessary to evaluate the results in these patients.

\section{ACKNOWLEDGEMENTS}

We appreciate the participation of Ernesto Roldan Valdez and Carlos Manuel Ortiz Mendoza for their valuable contributions to this paper.

\section{CONFLICTS OF INTEREST}

The authors declare no conflicts of interest

\section{ORCID}

Jair Díaz-Martínez: https://orcid.org/0000-0002-7581-6739

Oscar Chapa-Azuela:

https://orcid.org/0000-0002-9128-8577

Jorge Alberto Roldan-García:

https://orcid.org/0000-0002-4825-008X

Gustavo Alain Flores-Rangel:

https://orcid.org/0000-0001-7025-6552

\section{AUTHOR CONTRIBUTIONS}

Conceptualization: JDM. Data Curation: JDM, OCA, JARG, GAFR. Formal analysis: JDM, OCA. Funding acquisition: N/A. Methodology: JDM, OCA, JARG, GAFR. Project administration: JDM, OCA. Visualization: JDM. Writing - original draft: JDM, OCA. Writing - review and editing: JDM.

\section{REFERENCES}

1. Connor S, Garden OJ. Bile duct injury in the era of laparoscopic cholecystectomy. Br J Surg 2006;93:158-168.

2. Booij KAC, Coelen RJ, de Reuver PR, Besselink MG, van Delden OM, Rauws EA, et al. Long-term follow-up and risk factors for strictures after hepaticojejunostomy for bile duct injury: an analysis of surgical and percutaneous treatment in a tertiary center. Surgery 2018;163:1121-1127.

3. Mercado MÁ, Franssen B, Dominguez I, Arriola-Cabrera JC, Ramírez-Del Val F, Elnecavé-Olaiz A, et al. Transition from a low: to a high-volume centre for bile duct repair: changes in technique and improved outcome. HPB (Oxford) 2011;13: 767-773.

4. Martinez-Lopez S, Upasani V, Pandanaboyana S, Attia M, Toogood G, Lodge P, et al. Delayed referral to specialist centre increases morbidity in patients with bile duct injury (BDI) after laparoscopic cholecystectomy (LC). Int J Surg 2017;44:82-86.

5. Mercado MA. Early versus late repair of bile duct injuries. Surg Endosc 2006;20:1644-1647.

6. Pekolj J, Alvarez FA, Palavecino M, Sánchez Clariá R, Mazza $\mathrm{O}$, de Santibañes E. Intraoperative management and repair of bile duct injuries sustained during 10,123 laparoscopic cholecystectomies in a high-volume referral center. J Am Coll Surg 2013;216:894-901.

7. Strasberg SM, Hertl M, Soper NJ. An analysis of the problem of biliary injury during laparoscopic cholecystectomy. J Am Coll Surg 1995;180:101-125.

8. Bismuth H, Majno PE. Biliary strictures: classification based on the principles of surgical treatment. World J Surg 2001;25: 1241-1244.

9. Flores-Rangel GA, Chapa-Azuela O, Rosales AJ, Roca-Vasquez C, Böhm-González ST. Quality of life in patients with background of iatrogenic bile duct injury. World J Surg 2018;42: 2987-2991.

10. Strasberg SM, Eagon CJ, Drebin JA. The "hidden cystic duct" 
syndrome and the infundibular technique of laparoscopic cholecystectomy--the danger of the false infundibulum. J Am Coll Surg 2000;191:661-667.

11. Dominguez-Rosado I, Sanford DE, Liu J, Hawkins WG, Mercado MA. Timing of surgical repair after bile duct injury impacts postoperative complications but not anastomotic patency. Ann Surg 2016;264:544-553.

12. Tantia O, Jain M, Khanna S, Sen B. Iatrogenic biliary injury: 13,305 cholecystectomies experienced by a single surgical team over more than 13 years. Surg Endosc 2008;22:1077-1086.

13. Bobkiewicz A, Krokowicz Ł, Banasiewicz T, Kościński T, Borejsza-Wysocki M, Ledwosiński W, et al. Iatrogenic bile duct injury. A significant surgical problem. Assessment of treatment outcomes in the department's own material. Pol Przegl Chir 2015;86:576-583.

14. Rystedt J, Lindell G, Montgomery A. Bile duct injuries associated with 55,134 cholecystectomies: treatment and outcome from a national perspective. World J Surg 2016;40:73-80.

15. Shetty S, Desai PR, Vora HB, Bhavsar MS, Khiria LS, Yadav A, et al. Management of major postcholecystectomy biliary injuries: an analysis of surgical results in 62 patients. Niger J Surg 2019;25:91-96.

16. Ismael HN, Cox S, Cooper A, Narula N, Aloia T. The morbidity and mortality of hepaticojejunostomies for complex bile duct injuries: a multi-institutional analysis of risk factors and outcomes using NSQIP. HPB (Oxford) 2017;19:352-358.

17. Sicklick JK, Camp MS, Lillemoe KD, Melton GB, Yeo CJ, Campbell KA, et al. Surgical management of bile duct injuries sustained during laparoscopic cholecystectomy: perioperative results in 200 patients. Ann Surg 2005;241:786-792; discussion 793-795.

18. Mercado MA, Chan C, Orozco H, Cano-Gutiérrez G, Chaparro $\mathrm{JM}$, Galindo E, et al. To stent or not to stent bilioenteric anastomosis after iatrogenic injury: a dilemma not answered? Arch Surg 2002;137:60-63.

19. Stewart L, Way LW. Laparoscopic bile duct injuries: timing of surgical repair does not influence success rate. A multivariate analysis of factors influencing surgical outcomes. HPB (Oxford) 2009;11:516-522.

20. Kadaba RS, Bowers KA, Khorsandi S, Hutchins RR, Abraham AT, Sarker SJ, et al. Complications of biliary-enteric anastomoses. Ann R Coll Surg Engl 2017;99:210-215.

21. Gad EH, Ayoup E, Kamel Y, Zakareya T, Abbasy M, Nada A, et al. Surgical management of laparoscopic cholecystectomy (LC) related major bile duct injuries; predictors of short-and long-term outcomes in a tertiary Egyptian center- a retrospective cohort study. Ann Med Surg (Lond) 2018;36:219-230.

22. Otto W, Sierdziński J, Smaga J, Dudek K, Zieniewicz K. Long-term effects and quality of life following definitive bile duct reconstruction. Medicine (Baltimore) 2018;97:e12684. 